\title{
Impact of Aeromonas and diarrheagenic Escherichia coli screening in patients with diarrhea in Paraná, southern Brazil
}

\author{
Flávia EA Assis ${ }^{1}$, Suélen Wolf ${ }^{1}$, Monica Surek ${ }^{1}$, Fabiana De Toni ${ }^{2}$, Emanuel M Souza ${ }^{3}$, Fábio O \\ Pedrosa $^{3}$, Sônia MSS Farah ${ }^{4}$, Geraldo Picheth ${ }^{1}$, Cyntia MT Fadel-Picheth ${ }^{1}$ \\ ${ }^{1}$ Departamento de Patologia Médica, Universidade Federal do Paraná, Curitiba, PR, Brazil \\ ${ }^{2}$ Laboratório Municipal de Curitiba, Curitiba, PR, Brazil \\ ${ }^{3}$ Departamento de Bioquímica e Biologia Molecular, Universidade Federal do Paraná, Curitiba, PR, Brazil \\ ${ }^{4}$ Laboratório Central do Estado do Paraná, Curitiba, PR, Brazil
}

\begin{abstract}
Introduction: A wide diversity of bacterial agents may cause diarrhea, presenting challenges to clinical laboratories to define a diagnosis. Considering that most stool cultures are negative, we screened stool samples from patients with diarrhea for the presence of 14 bacterial enteropathogens, aiming to establish which of them should be included in routine stool analysis.

Methodology: Stool samples from 400 patients with diarrhea were analyzed for the presence of Salmonella, Shigella, Campylobacter, Aeromonas, Plesiomonas shigelloides, Vibrio, Yersinia enterocolitica, and diarrheagenic Escherichia coli using conventional microbiological methods and PCR. Two distinct samples were studied; one included predominantly patients involved in outbreaks, and the other patients of low socioeconomic status presenting sporadic cases of diarrhea.

Results: In total, 86 cultures $(21.5 \%)$ were positive. Mixed infections were found in five patients, leading to recovery of 91 strains of enteropathogenic bacteria: Salmonella Enteritidis (9.2\%), Aeromonas (7.2\%), diarrheagenic E. coli (5.2\%), and C. jejuni (1\%). However, Salmonella predominated, with $11.5 \%$ frequency in diarrhea outbreaks, while Aeromonas predominated among patients of low socioeconomic status, with $14.6 \%$ frequency.

Conclusion: Aeromonas and diarrheagenic E. coli, which are not routinely screened for, deserve to be included in laboratory screening panels.
\end{abstract}

Key words: diarrhea; bacterial enteropathogens; prevalence; laboratory diagnosis; gastroenteritis agents.

J Infect Dev Ctries 2014; 8(12):1609-1614. doi:10.3855/jidc.4434

(Received 20 November 2013 - Accepted 21 March 2014)

Copyright (C) 2014 Assis et al. This is an open-access article distributed under the Creative Commons Attribution License, which permits unrestricted use, distribution, and reproduction in any medium, provided the original work is properly cited.

\section{Introduction}

Diarrheal diseases represent a major health problem in developing countries and are also a risk to travellers who visit these countries [1]. It is estimated that, worldwide, more than one billion episodes of diarrhea occur annually, causing about two million deaths per year, ranking third among all causes of infectious diseases-related deaths [1,2]. Furthermore, some bacterial agents of infectious diarrhea may cause serious long-term sequelae such as hemolytic uremic syndrome, Guillain-Barré syndrome, and malnutrition, in addition to acute morbidity and mortality. The wide diversity of bacterial agents that may cause diarrhea complicates accurate surveillance and diagnosis [1-3]. Moreover, defining etiology of acute diarrhea is critical to disease therapy and prevention [4].

Laboratory analysis of stool specimens and identification of enteric pathogens are dependent upon numerous conditions, and no one set of conditions is ideal for all bacterial enteropathogens. Stool analysis in many cases can be extremely challenging, especially when enteropathogens other than Campylobacter, Salmonella, and Shigella are sought. Furthermore, stool cultures are expensive to perform, and decisions need to be made about how much effort and expense should be allowed to establish a definitive diagnosis [3]. We undertook this study to determine the presence of 14 bacterial enteropathogens in stool samples from patients with diarrhea, aiming to establish which of them should be included in routine stool analysis in our geographic region.

\section{Methodology}

Study design

This prospective study screened for 14 bacterial enteropathogens in stool samples from patients with diarrhea in Paraná state, southern Brazil. The criteria used for inclusion of patients with diarrhea was the 
emission of three or more liquid or loose stools within a 24-hour period.

\section{Sample collection and classification}

Two groups were established. Group $1(\mathrm{n}=305)$ included samples from patients involved in 11 foodborne outbreaks that occurred in several localities of Paraná state, and serious cases of sporadic diarrhea. The samples of group $2(n=95)$ were exclusively from patients of low socioeconomic status with sporadic diarrhea who attended the county laboratory of Curitiba, Paraná, southern Brazil. These patients presented mild to moderate diarrhea and complaints of abdominal pain; some complained of persistent diarrhea.

The stool samples of the 400 patients with diarrhea, who included adults and children, were collected between September 2010 and December 2011. Stool samples were transported in Cary-Blair medium at $4^{\circ} \mathrm{C}$ and maintained under refrigeration until the moment of analysis.

\section{Laboratory procedure}

The 400 stool samples were analyzed for the presence of Salmonella, Shigella, Aeromonas, Plesiomonas shigelloides, Campylobacter, Vibrio, and Yersinia enterocolitica using conventional microbiological methods [5-10], and for diarrheagenic Escherichia coli using a two-system multiplex polymerase chain reaction (PCR). Salmonella serotyping was performed at the national reference laboratory Fundação Oswaldo Cruz (Fiocruz), using antisera prepared at the same institution.

\section{Multiplex PCR}

The procedure described in [11] was followed. Briefly, for screening of diarrheagenic E. coli (DEC), the stool samples were inoculated in MacConkey agar. After overnight incubation at $36^{\circ} \mathrm{C}$, a loopful of the area of confluent growth was resuspended in $500 \mu \mathrm{L}$ of sterile water and used for DNA extraction by the boiling method. The extracts were centrifuged at $14,000 \mathrm{rpm}$ for two minutes, and $3 \mu \mathrm{L}$ of the supernatants were used in the two-system multiplexPCR method developed by Fialho et al. [11]. The multiplex-PCR system 1 contains primers for detection of Shiga-toxin producing E. coli (STEC; stx1, stx2), enteropathogenic $E$. coli (EPEC; eae, $b f p A$ ), atypical enteropathogenic $E$. coli (aEPEC; eae), enterotoxigenic $E$. coli (ETEC; $l t, s t$ ), enteroinvasive E. coli (EIEC; ial), and the internal control $16 \mathrm{~S}$ rRNA to validate the negative results. The multiplex-PCR system 2 contains primers for detection of EIEC (ipaH), enteroaggregative E. coli (EAEC, CVD432), diffusely adherent E. coli (DAEC, daaE), and the internal amplification control $16 \mathrm{~S}$ rRNA. Samples positive in this step then had up to 50 isolated colonies tested individually by single PCR for the specific DEC marker. PCR reactions were performed in a final volume of $25 \mu \mathrm{L}$, containing Taq DNA polymerase buffer $1 \times$ (Invitrogen, Waltham, USA), $1.5 \mathrm{mM}$ $\mathrm{MgCl} 2,0.2 \mathrm{mM}$ dNTP, $1 \mathrm{U}$ of Taq DNA polymerase platinum (Invitrogen), and $3 \mu \mathrm{L}$ of template DNA. The concentration of each pair of primers was adjusted empirically to obtain DNA bands of similar intensities with controls. The cycling programs used were 1 cycle at $94^{\circ} \mathrm{C}$ (4 minutes), 35 cycles at $94^{\circ} \mathrm{C}$ ( 1 minute), $55^{\circ} \mathrm{C}$ ( 1 minute), $72^{\circ} \mathrm{C}$ ( 1 minute), and a final cycle at $72^{\circ} \mathrm{C}$ (5 minutes) for multiplex-PCR system 1; for system 2, the conditions were the same except the annealing temperature that was $58^{\circ} \mathrm{C}$ (1 minute). Detection of PCR products was by electrophoresis in $2 \%$ agarose gel stained with ethidium bromide and visualized under UV light.

The antimicrobial susceptibility test was performed using the disk diffusion method, and the Etest was also used for Campylobacter [12,13].

\section{Statistical analysis}

Statistical analysis was performed with Statistica version 8.0 software (StatSoft Inc., Tulsa, USA), using Fisher's exact test (two-tailed) with Bonferroni correction. A p-value $<0.05$ was considered significant.

\section{Results}

Bacterial enteropathogens were recovered from 86 $(21.5 \%)$ stool cultures, of which $61(20 \%)$ and 25 (26\%), respectively, were from groups 1 and 2 . No statistically significant difference was observed in the number of positive cultures between samples from groups 1 and $2(\mathrm{p}=0.199)$. Mixed infections were found in five samples, one from group 2 in which $A$. hydrophila and aEPEC were recovered. In the four other samples, Salmonella was isolated together with aEPEC, DAEC, A. caviae, or Aeromonas spp. In total, 91 bacterial enteropathogenic strains were recovered, including Salmonella ser. Enteritidis (9.2\%), Aeromonas (7.2\%), diarrheagenic E. coli (5.2\%), and C. jejuni (1\%) (Table 1). These bacteria were isolated from patients of all ages; no significant difference was found in their frequencies among patients of different age groups. ETEC, EIEC, Shigella, P. shigelloides, Vibrio, and $Y$. enterocolitica were not found. 
Antimicrobial susceptibility testing showed that most Salmonella (33/37) were resistant to nalidixic acid. Resistance was also observed to tetracycline (five strains), chloramphenicol (four strains), ampicillin (three strains), trimethoprim-sulfamethoxazole (three strains), and cefalotin (two strains); four strains were multiresistant. All Salmonella strains were susceptible to the following antimicrobials: amoxicillin-clavulanic acid, aztreonam, cefoxitin, ceftazidime, ceftriaxone, ciprofloxacin, ertapenem, gentamicin, imipenem, levofloxacin, and meropenem. Among Aeromonas, only one strain was susceptible to all the antimicrobials tested, and all but this strain were resistant to ampicillin. Most Aeromonas (23/29) were also resistant to cefalotin and cefazolin. This was expected since most of Aeromonas are resistant to these antimicrobials [10]. Resistance to the following antimicrobials was also observed: amoxicillinclavulanic acid (six strains), cefoxitin (five strains), trimethoprim-sulfamethoxazole and nalidixic acid (four strains), tetracycline (two strains), and chloramphenicol (one strain). Six strains were multiresistant. All Aeromonas strains were susceptible to amikacin, aztreonam, cefepime, cefotaxime, ceftazidime, ceftriaxone, ciprofloxacin, imipenem, levofloxacin, and meropenem. Among the 21 DEC strains, 10 were susceptible to all antimicrobials tested (amoxicillin-clavulanic acid, ampicillin, aztreonam, cefalotin, cefepime, cefotaxime, cefoxitin, ceftazidime, ceftriaxone, ciprofloxacin, gentamicin, imipenem, piperacillin-tazobactam, tetracycline, and trimethoprim-sulfamethoxazole). Ampicillin resistance was observed in only ten strains (four aEPEC, three
EAEC, and three DAEC), and one aEPEC was resistant to ampicillin and cefalotin. For C. jejuni, the antimicrobials tested were tetracycline, erythromycin, and ciprofloxacin. One strain was susceptible to all of them, two were resistant to ciprofloxacin, and one was resistant to tetracycline and ciprofloxacin.

\section{Discussion}

Over the past 20 years, the number of bacterial species involved in diarrheal syndromes has increased, challenging the laboratory diagnosis of bacterial diarrhea [3].

In our geographic region, most stool cultures are negative. Therefore, we conducted a prospective study screening stool samples from patients with diarrhea for the presence of 14 bacterial enteropathogens to establish their prevalence.

Overall, Salmonella enterica ser. Enteritidis was the bacteria recovered most frequently (Table 1). However, the frequency of Salmonella in stool cultures of patients from group 1 was significantly higher $(\mathrm{p}=0.004)$ than that found in patients from group 2 (Table 1). Since group 1 contained mainly patients involved in outbreaks, this indicates that Salmonella is the most common bacteria involved in outbreaks of diarrhea. In contrast, Salmonella (2.1\%) only ranked fourth, together with EAEC and behind $A$. caviae (10.5\%), aEPEC (4.2\%), and A. hydrophila $(3.1 \%)$, among patients of low socioeconomic status with sporadic diarrhea (group 2). No significant difference was found in the distribution of the other enteropathogens between both groups (Table 1). However, if all strains of Aeromonas are taken

Table 1. Frequencies of bacterial enteropathogens found in stool cultures of patients from groups 1 and 2

\begin{tabular}{|c|c|c|c|}
\hline Bacteria $(\mathrm{N}=91)$ & Group 1 & Group 2 & $P^{*}$ \\
\hline Salmonella enterica ser. Enteritidis (9.2\%) & $35(11.5 \%)$ & $2(2.1 \%)$ & 0.004 \\
\hline Aeromonas caviae $(5.2 \%)$ & $11(3.6 \%)$ & $10(10.5 \%)$ & 0.015 \\
\hline Aeromonas spp. $(0.5 \%)$ & $1(0.3 \%)$ & $1(1 \%)$ & 0.419 \\
\hline aEPEC $(3.2 \%)$ & $9(2.9 \%)$ & $4(4.2 \%)$ & 0.517 \\
\hline $\operatorname{EAEC~}(0.7 \%)$ & $1(0.3 \%)$ & $2(2.1 \%)$ & 0.142 \\
\hline $\operatorname{STEC}(0.2 \%)$ & 0 & $1(1.0 \%)$ & 0.237 \\
\hline $\mathrm{tEPEC}(0.2 \%)$ & 0 & $1(1.0 \%)$ & 0.237 \\
\hline Campylobacter jejuni (1.0\%) & $3(1.0 \%)$ & $1(1.0 \%)$ & 1.000 \\
\hline
\end{tabular}

The values are number of enteropathogens isolated, $\mathrm{n}(\%)$.

Group $1(\mathrm{n}=305)$ patients from outbreaks and serious cases of sporadic diarrhea, 61 positive cultures, 4 of which were mixed infection $(\mathrm{a}$ total of 65 enteropathogens isolated); Group $2(\mathrm{n}=95)$, patients of low socioeconomic status with sporadic diarrhea, 25 positive cultures and 1 mixed infection (total of 26 enteropathogens isolated).

"P: Fisher's exact text (two-tailed). Significant p-value with Bonferroni correction $0.005(0.05 / 10)$. 
together, their prevalence among patients in group 2 is three times higher than among patients in group 1 (14/95 vs. $15 / 305 ; p=0.001)$. Aeromonas were the second most frequently isolated enteropathogens (Table 1), and were recovered both from children (15 strains) and adults (14 strains). It is worth remembering that most routine clinical laboratories do not screen for Aeromonas, and our results indicate that these enteropathogens were responsible for the majority of sporadic diarrhea cases (Table 1).

Aeromonas are causes of infectious diarrhea $[2,3]$ and are also agents of traveler's diarrhea $[3,14]$. They are ubiquitous in aquatic environments and are transmitted to humans through contaminated water $[3,15]$ and food $[16]$.

Aeromonas have been reported as cause of diarrhea in several countries. Their incidence varies widely around the world, from $0.04 \%$ in Crete [17], $1.7 \%$ in Israel [18], 2\% in Sweden [19], $4.8 \%$ in Switzerland [20], $3.1 \%$ to $6.5 \%$ in India [21], 3.9\% to $25.9 \%$ and $3.2 \%$ to $32.3 \%$ in Bangladesh and Pakistan, respectively [22], and from $2.6 \%$ to $19.5 \%$ in Brazil [23-25].

Interestingly, the frequency of Aeromonas found here is significantly higher $(\mathrm{p}=0.003)$ than that found in our previous study using stool samples from patients who attended private clinical laboratories, of whom 2.6\% were found to have Aeromonas infections [23]. It is known that development of infectious diarrhea is related to environmental conditions including poor sanitation and hygiene, unsafe water supplies, poor education, and inadequate sewage disposal [2]. Since this sample comprised patients of low socioeconomic status, among whom a higher incidence of Aeromonas was found (Table 1), the difference in the prevalence of these bacteria between the two studies realized with patients of the same geographical area is probably related to the distinct living conditions of the people.

Considering our results, and also that Aeromonas has been found as a diarrhea agent in several studies, including some realized in developed countries [1820], we suggest that these bacteria should be included in the panel of enteropathogens screened for in routine laboratory tests.

Detection of DEC requires specialized tests [3], since they are indistinguishable from $E$. coli commensal strains based on biochemical tests. In addition, serotyping is rarely sufficient to reliably identify a strain as diarrheagenic. In this study, we used multiplex PCR for detection of virulence genes that characterize the DEC pathotypes [11]. The DEC strains ranked third among the enteropathogens recovered, with a frequency of $5.2 \%$, with atypical EPEC being the predominant pathotype among them (Table 1). These strains are increasingly being implicated as important causes of gastroenteritis around the world [3]. In Switzerland, a frequency of $8 \%$ of DEC was found among children with diarrhea [20], while among Caribbean-Colombian children, a rate of $14.4 \%$ was reported [26], and in Brazil, rates from $7.6 \%$ to $48 \%$ [11,27-30] have been reported. In India, a frequency of $52 \%$ of DEC was found among children under five years of age with diarrhea [31], and in Ghana, these bacteria were recovered from $77 \%$ of children and $38 \%$ of adults with diarrhea [32]. These studies also showed that DEC are important causes of diarrhea. Based on these data and our results, we suggest that a search for DEC pathotypes is included in routine screening.

We also found $C$. jejuni as a diarrhea agent. Although these bacteria are among the most frequently isolated from patients with diarrhea $[1,3]$, in our study, they only ranked fifth, after Salmonella, A. caviae, aEPEC, and A. hydrophila.

Also, since multiresistant strains were detected, we strongly recommend that antimicrobial susceptibility tests always be performed.

\section{Conclusions}

In summary, this study showed the prevalence of several enteropathogens in culture stools of people with diarrhea, some of which are not routinely screened by diagnostic laboratories. Based upon the frequency of Aeromonas and diarrheagenic E. coli recovery, which together represent $60 \%$ of the positive cultures, we suggest that these bacteria should be included in the panel of bacterial enteropathogens routinely screened for in stool cultures.

\section{Acknowledgements}

This study was supported by Fundação Araucária; the Brazilian Program of National Institutes of Science and Technology - INCT/Brazilian Research Council $\mathrm{CNPq} / \mathrm{MCT}$; and CAPES/REUNI. 


\section{References}

1. World Health Organization (2009) Diarrhoeal Diseases. Geneva: WHO. Available: http://www.who.int/vaccine_research/diseases/diarrhoeal/en/i ndex.html. Accessed 15 August 2012.

2. Gadewar S, Fasano A (2005) Current concepts in the evaluation, diagnosis and management of acute infectious diarrhea. Curr Opin Pharmacol 5: 559-565.

3. Janda JM, Abbott SL (2011) Revisiting bacterial gastroenteritis, Part I: Issues, possible approaches, and an ever-expanding list of etiologic agents. Clin Microbiol Newsletter 33: 71-76.

4. Marcos LA, DuPont HL (2007) Advances in defining etiology and new therapeutic approaches in acute diarrhea. J Infect 55: 385-393.

5. Farmer III JJ (2003) Enterobacteriaceae: introduction and identification. In: Murray PR, Baron EJ, Jorgensen JH, editors. Manual of Clinical Microbiology. Washington: ASM Press. 636-653.

6. Bopp CA, Brenner FW, Fields PI, Wells JG, Strockbine NA (2003) Escherichia, Salmonella and Shigella identification. In: Murray PR, Baron EJ, Jorgensen JH, Pfaller MA, Yolken RH editors. Manual of Clinical Microbiology. Washington: ASM Press. 654-671.

7. Bockemühl J, Wong JD (2003) Yersinia. In: Murray PR, Baron EJ, Jorgensen JH, editors. Manual of Clinical Microbiology. Washington: ASM Press. 672-683.

8. Horneman AJ, Ali A, Abbott SL (2007) Aeromonas. In: Murray PR, Baron EJ, Jorgensen JH, editors. Manual of Clinical Microbiology. Washington:: ASM Press. 716-721.

9. Nachamkin I (2003) Campylobacter and Arcobacter. In: Murray PR, Baron EJ, Jorgensen JH, editors. Manual of Clinical Microbiology. Washington: ASM Press. 902-914.

10. Abbott SL, Cheung WKW, Janda JM (2003) The genus Aeromonas: biochemical characteristics, atypical reactions, and phenotypic identification schemes. J Clin Microbiol 41: 2348-2357.

11. Fialho OB, Souza EM, Dallagassa CB, de Oliveira Pedrosa F, Klassen G, Irino K, Paludo KS, de Assis FE, Surek M, de Souza Santos Farah SM, Fadel-Picheth CM (2013) Detection of diarrheagenic Escherichia coli using a two-system multiplex-PCR protocol. J Clin Lab Anal 27: 155-161.

12. Clinical and Laboratory Standards Institute (2010) Methods for antimicrobial dilution and disk susceptibility testing of infrequently isolated fastidious bacteria; approved guideline, 2nd edition. M45-A2. Wayne, PA: CLSI.

13. Clinical and Laboratory Standards Institute (2011) Performance standards for antimicrobial susceptibility testing; twenty-first informational supplement M100-S21. Wayne, PA: CLSI.

14. Vila J, Ruiz J, Gallardo F, Vargas M, Soler L, Figueras MJ, Gascon J (2003) Aeromonas spp. and traveler's diarrhea: clinical features and antimicrobial resistance. Emerg Infect Dis 9: $552-555$.

15. Khajanchi BK, Fadl AA, Borchardt MA, Berg RL, Horneman AJ, Stemper ME, Joseph SW, Moyer NP, Sha J, Chopra AK (2010) Distribution of virulence factors and molecular fingerprinting of Aeromonas species isolates from water and clinical samples: suggestive evidence of water-to-human transmission. Appl Environ Microbiol 76: 2313-2325.

16. Janda JM, Abbott SL (2010) The Genus Aeromonas: Taxonomy, Pathogenicity, and Infection. Clin Microbiol Rev 23: $35-73$.
17. Maraki S, Georgiladakis A, Tselentis Y, Samonis G (2003) A 5 -year study of the bacterial pathogens associated with acute diarrhoea on the island of Crete, Greece, and their resistance to antibiotics. Eur J Epidemiol 18: 85-90.

18. Senderovich Y, Ken-Dror S, Vainblat I, Blau D, Izhaki I, Halpern M (2012) A molecular study on the prevalence and virulence potential of Aeromonas spp. recovered from patients suffering from diarrhea in Israel. PLoS ONE 7: e30070.

19. Svenungsson B, Lagergren A, Ekwall E, Evengård B, Hedlund KO, Kärnell A, Löfdahl S, Svensson L, Weintraub A (2000) Enteropathogens in adult patients with diarrhea and healthy control subjects: a 1-year prospective study in a Swedish clinic for infectious diseases. Clin Infect Dis 30: 770-778.

20. Essers B, Burnens AP, Lanfranchini FM, Somaruga SG, von Vigier RO, Schaad UB, Aebi C, Bianchetti MG (2000) Acute community-acquired diarrhea requiring hospital admission in Swiss children. Clin Infect Dis 30: 192-196.

21. Sinha S, Shimada T, Ramamurthy T, Bhattacharya SK, Yamasaki S, Takeda Y, Nair GB (2004) Prevalence, serotype distribution, antibiotic susceptibility and genetic profiles of mesophilic Aeromonas species isolated from hospitalized diarrhoeal cases in Kolkata, India. J Med Microbiol 53: 527534.

22. Kotloff KL, Nataro JP, Blackwelder WC, Nasrin D, Farag $\mathrm{TH}$, Panchalingam S, Wu Y, Sow SO, Sur D, Breiman RF, Faruque AS, Zaidi AK, Saha D, Alonso PL, Tamboura B, Sanogo D, Onwuchekwa U, Manna B, Ramamurthy T, Kanungo S, Ochieng JB, Omore R, Oundo JO, Hossain A, Das SK, Ahmed S, Qureshi S, Quadri F, Adegbola RA, Antonio M, Hossain MJ, Akinsola A, Mandomando I, Nhampossa T, Acácio S, Biswas K, O'Reilly CE, Mintz ED, Berkeley LY, Muhsen K, Sommerfelt H, Robins-Browne RM, Levine MM (2013) Burden and aetiology of diarrhoeal disease in infants and young children in developing countries (the Global Enteric Multicenter Study, GEMS): a prospective, case-control study. Lancet 382: 209-222.

23. Surek M, Vizzotto BS, Souza EM, Pedrosa Fde O, Dallagassa CB, Farah SM, Fadel-Picheth CM (2010) Identification and antimicrobial susceptibility of Aeromonas spp. isolated from stool samples of Brazilian subjects with diarrhoea and healthy controls. J Med Microbiol 59: 373-374.

24. Guerra IMF, Fadanelli R, Figueiró M, Schreiner F, Delamare APL, Wollheim C, Costa SOP, Echeverrigaray S (2007) Aeromonas associated diarrhoeal disease in South Brazil: prevalence, virulence factors and antimicrobial resistance. Braz J Microbiol 38: 638-643.

25. Hofer ER, Reis CMF, Theophilo GND, Cavalcanti VO, Lima NV, Henriques Mde F (2006) Envolvimento de Aeromonas em surto de doença diarréica aguda em São Bento do Una, Pernambuco. Rev Soc Bras Med Trop 39: 217-220.

26. Gómez-Duarte OG, Arzuza O, Urbina D, Bai J, Guerra J, Montes O, Puello M, Mendoza K, Castro GY (2010) Detection of Escherichia coli enteropathogens by multiplex polymerase chain reaction from children's diarrheal stools in two Caribbean-Colombian cities. Foodborne Pathog Dis 7:199-206.

27. Orlandi PP, Magalhães GF, Matos NB, Silva T, Penatti M, Nogueira PA, Silva LH (2006) Etiology of diarrheal infections in children of Porto Velho (Rondonia), Western Amazon region, Brazil.. Braz J Med Biol Res 39: 507-517. 
28. Bueris V, Sircili MP, Taddei CR, dos Santos MF, Franzolin MR, Martinez MB, Ferrer SR, Barreto ML, Trabulsi LR (2007) Detection of diarrheagenic Escherichia coli from children with and without diarrhea in Salvador, Bahia, Brazil. Mem Inst Oswaldo Cruz 102: 839-844.

29. Aranda KRS, Fabbricotti SH, Fagundes-Neto U, Scaletsky ICA (2007) Single multiplex assay to identify simultaneously enteropathogenic, enteroaggregative, enterotoxigenic, enteroinvasive and Shiga toxin-producing Escherichia coli strains in Brazilian children. FEMS Microbiol Lett 267: 145150.

30. Moreno ACR, Filho AF, Gomes TA, Ramos ST, Montemor LP, Tavares VC, Filho Ldos S, Irino K, Martinez MB (2010) Etiology of childhood diarrhea in the northeast of Brazil: significant emergent diarrheal pathogens. Diagn Microbiol Infect Dis 66: 50-57.
31. Rajendran $\mathrm{P}$, Ajjampura SSR, Chidambarama D, Chandrabose G, Thangaraj B, Sarkar R, Samuel P, Rajan DP, Kang G (2010) Pathotypes of diarrheagenic Escherichia coli in children attending a tertiary care hospital in South India. Diagn Microbiol Infect Dis 68: 117-122.

32. Opintan JA, Bisharb RA, Newman MJ, Okeke IN (2010) Carriage of diarrhoeagenic Escherichia coli by older children and adults in Accra, Ghana. Transactions of the Royal Society of Tropical Medicine and Hygiene 104: 504-506.

\section{Corresponding author}

Cyntia M T Fadel-Picheth

Universidade Federal do Paraná, Campus Jardim Botânico

Av. Prefeito Lothário Meissner 632, Jardim Botânico, Curitiba CEP 80210-170, Paraná, Brazil

Phone: $+55-41-33604086$

Fax: +55-41-33604101

Email: fpicheth@ufpr.br

Conflict of interests: No conflict of interests is declared. 